NASA Technical Memorandum 4494

\title{
Preliminary Supersonic Flight Test Evaluation of Performance Seeking Control
}

John S. Orme and Glenn B. Gilyard

JUNE 1993

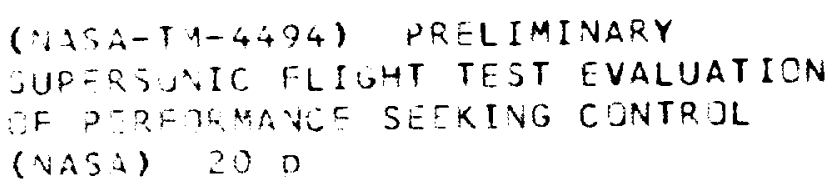


$m$ 
NASA Technical Memorandum 4494

\section{Preliminary Supersonic Flight Test Evaluation of Performance Seeking Control}

John S. Orme and Glenn B. Gilyard Dryden Flight Research Facility

Edwards, California

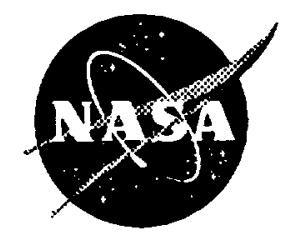

National Aeronautics and Space Administration Office of Management Scientific and Technical Information Program 



\title{
PRELIMINARY SUPERSONIC FLIGHT TEST EVALUATION OF PERFORMANCE SEEKING CONTROL
}

\author{
John S. Orme* \\ and \\ Glenn B. Gilyard** \\ NASA Dryden Flight Research Facility \\ P.O. Box 273 \\ Edwards, California
}

\begin{abstract}
Digital flight and engine control, powerful onboard computers, and sophisticated controls techniques may improve aircraft performance by maximizing fuel efficiency, maximizing thrust, and extending engine life. An adaptive performance seeking control system for optimizing the quasi-steady state performance of an F-15 aircraft has been developed and flight tested. This system has three optimization modes: minimum fuel, maximum thrust, and minimum fan turbine inlet temperature. Tests of the minimum fuel and fan turbine inlet temperature modes were performed at a constant thrust. Supersonic single-engine flight tests of the three modes were conducted using varied afterburning power settings. At supersonic conditions, the performance seeking control law optimizes the integrated airframe, inlet, and engine. At subsonic conditions, only the engine is optimized. Supersonic flight tests showed improvements in thrust of 9 percent, increases in fuel savings of 8 percent, and reductions of up to $85^{\circ} \mathrm{R}$ in turbine temperatures for all three modes. This paper describes the supersonic performance seeking control structure and gives preliminary results of supersonic performance seeking control tests. These findings have implications for improving performance of civilian and military aircraft.
\end{abstract}

\section{Nomenclature}

\section{$\mathrm{A} / \mathrm{B}$ \\ $A J$ afterburner \\ $C I V V$ nozzle throat area, in ${ }^{2}$ \\ compressor inlet variable guide vane angle, deg}

\footnotetext{
Aerospace Engineer, Member AIAA.

**Aerospace Engineer, Member AIAA.

Copyright (C) 1993 by the American Institute of Aeronautics and Astronautics, Inc. No copyright is asserted in the United States under Title 17, U.S. Code. The U.S. Government has a royalty-free license to exercise all rights under the copyright claimed herein for Governmental purposes. All other rights are reserved by the copyright owner.
}

\begin{tabular}{|c|c|}
\hline$C S P$ & control surface position, deg \\
\hline DEEC & digital electronic engine control \\
\hline DFRF & $\begin{array}{l}\text { Dryden Flight Research Facility, } \\
\text { Edwards, California }\end{array}$ \\
\hline$D I N L T$ & incremental inlet spillage drag, lbf \\
\hline$D N O Z$ & incremental nozzle drag, lbf \\
\hline$D T R I M$ & $\begin{array}{l}\text { incremental trim drag for the cowl and } \\
\text { stabilator, lbf }\end{array}$ \\
\hline EPR & engine pressure ratio, $P T 6 / P T 2$ \\
\hline$F N$ & net thrust, lbf \\
\hline$F N P$ & net propulsive force, lbf \\
\hline FTIT & fan turbine inlet temperature, ${ }^{\circ} \mathrm{R}$ \\
\hline HIDEC & $\begin{array}{l}\text { highly integrated digital electronic } \\
\text { control }\end{array}$ \\
\hline$h_{c}$ & capture height, $\mathrm{ft}$ \\
\hline Kf & Kalman filter \\
\hline McAir & $\begin{array}{l}\text { McDonnell Aircraft Company, } \\
\text { St. Louis, Missouri }\end{array}$ \\
\hline NASA & $\begin{array}{l}\text { National Aeronautics and Space } \\
\text { Administration }\end{array}$ \\
\hline$N 1$ & fan rotor speed, rpm \\
\hline$N 1 C 2$ & $\begin{array}{l}\text { fan rotor speed, corrected to engine face, } \\
\text { rpm }\end{array}$ \\
\hline$N 2$ & compressor rotor speed, rpm \\
\hline P \& W & $\begin{array}{l}\text { Pratt \& Whitney, West Palm Beach, } \\
\text { Florida }\end{array}$ \\
\hline PT4 & burner pressure, $\mathrm{lb} / \mathrm{in}^{2}$ \\
\hline PCTC & percent inlet critical mass flow \\
\hline PSC & performance seeking control \\
\hline$P S 2$ & static pressure at engine face, $\mathrm{lb} / \mathrm{in}^{2}$ \\
\hline$P T 2$ & total pressure at engine face, $\mathrm{lb} / \mathrm{in}^{2}$ \\
\hline$P T 6$ & augmenter inlet total pressure, $\mathrm{lb} / \mathrm{in}^{2}$ \\
\hline
\end{tabular}




$\begin{array}{ll}R C V V & \begin{array}{l}\text { rear compressor variable guide vane } \\ \text { angle, deg }\end{array} \\ S D R & \text { shock displacement ratio, } Y / h_{c} \\ T S F C & \text { thrust specific fuel consumption, } \mathrm{sec}^{-1} \\ T T 2 & \text { total temperature at engine face, }{ }^{\circ} \mathrm{R} \\ T T 4.5 & \text { turbine inlet total temperature, }{ }^{\circ} \mathrm{R} \\ V V & \text { variable vanes, } \mathrm{deg} \\ W F & \text { core fuel flow, lb/hr } \\ W F A B & \text { afterburner fuel flow, lb/hr } \\ W C F A N & \text { fan air flow, lb/sec } \\ Y & \text { perpendicular distance the third shock } \\ & \text { stands from the cowl lip, } \mathrm{ft}\end{array}$

Prefix

$\Delta$

difference

\section{Introduction}

Improving propulsion cycle efficiency and increasing aircraft performance is of interest to the aircraft industry because of the need to meet commercial and military demands. Applying optimal control technology to the integrated engine and airframe system is one method of meeting these demands. Digital flight and engine control provide the means of practically applying real-time optimal control technology to a complex system, such as an integrated engine and airframe.

To develop this optimal performance technology base, NASA Dryden Flight Research Facility (DFRF), Edwards, California, McDonnell Aircraft Company (McAir), St. Louis, Missouri, and Pratt \& Whitney (P \& W), West Palm Beach, Florida, developed and flight tested an adaptive performance seeking control (PSC) system for optimizing the quasi-steady state performance of the F-15 aircraft propulsion system. The PSC approach of model-based real-time optimization $^{1}$ is aided by an adaptive estimation of unmeasured propulsion system parameters. ${ }^{2}$ The PSC system has three optimization modes: minimum fuel, maximum thrust, and minimum fan turbine inlet temperature $(F T I T)$. The minimum fuel and FTIT modes are performed at a constant thrust. In subsonic flight testing, these modes improved performance over the baseline aircraft. ${ }^{3-6}$

Supersonic single-engine flight tests conducted at DFRF used the three PSC optimization modes at various afterburning power settings. At supersonic flight conditions, the PSC law optimizes the integrated airframe, inlet, and engine; whereas, for subsonic flight conditions, only the engine is optimized. Supersonic PSC has increased complexity because control of the inlet shocks, afterburner (A/B), and aircraft stabilator is included. Predicted supersonic results indicate performance improvements equal to or greater than those achieved subsonically, especially in the minimum fuel mode. ${ }^{7}$

This paper presents preliminary PSC flight test results of the three modes at Mach numbers up to 2 . Comparisons of algorithm performance when operating with or without inlet and stabilator optimization are made. In addition, quanitative results for each mode and a summary of initial supersonic fight test results are given.

\section{Aircraft Description}

The PSC program was implemented on the NASA F-15 research airplane (Fig. 1). This modified highperformance fighter-aircraft is capable of speeds in excess of Mach 2 and is powered by two PW1128 afterburning turbofan engines $(P \& W)$ with variablegeometry inlets. ${ }^{8}$

\section{F100 Engine}

This PW1128 engine is a low-bypass ratio, twinspool, afterburning turbofan technology demonstrator derived from the F100-PW-100 engine (P \& W). ${ }^{8}$ Figure 2 shows the $\mathrm{F} 100$ and the locations of its instrumentation sensors. The engine control effectors include compressor inlet variable vane angle $(C I V V)$, rear compressor variable vane angle $(R C V V)$, main burner core fuel flow $(W F)$, afterburner fuel flow $(W F A B)$, and nozzle throat area $(A J)$. This engine is controlled by a full-authority digital electronic engine control system (DEEC) that is similar to the production F100-PW-220 engine controller. ${ }^{9}$ The DEEC provides closed-loop control of corrected fan rotor speed $(N 1 C 2)$ through the $W F$ and of the engine pressure ratio (EPR) through the $A J$. The $C I V V$ and $R C V V$ positions are scheduled on rotor speeds through openloop control. The DEEC software has been modified to accept PSC trim commands; however, the normal DEEC control loops, that is, $N 1 C 2$ and EPR, have not been modified.

\section{Variable-Geometry Inlet}

The F- 15 has two-dimensional variable-geometry external compression inlets (Fig. 3). Compression is accomplished through three oblique shocks and a normal shock during supersonic operation. Two actuators provide independent control of the first ramp, or cowl, and the third ramp. Variable-inlet geometry is controlled by the digital inlet control unit on the basis of schedules as a function of Mach number, angle of attack, and freestream total temperature. Conservative schedules for inlet position were designed as a compromise between safety and performance although safety was of upmost importance. Basing inlet schedules on worst-case conditions avoids excessive inlet distortion; thus, engine 
and aircraft safety are assured. Worst-case conditions include maneuvering flight. Minimizing net drag is of secondary importance in the inlet schedules. Therefore, with some maneuver accommodation logic, inlet performance may be improved.

Repositioning of the inlet ramps produces aerodynamic forces and moments as well as changes to inlet recovery, which affects engine performance. Thus, coupling of the engines and airframe results from the variable-geometry inlets. As such, engine and airframe integration for PSC is accomplished primarily by controlling the inlets.

\section{Stabilator Control}

The stabilator is the only longitudinal effector which provides pitch trim control of the F-15 aircraft. As noted, however, the inlets also impart aerodynamic forces and moments to the airframe. The stabilator responds to a repositioned inlet through aircraft innerand outer-loop control.

\section{Supersonic Performance Seeking Control Algorithm}

As developed by McAir, the PSC is a model-based, adaptive algorithm which performs real-time optimization of the propulsion system during quasi-steady state operation. Airdata, flight control parameters, and engine measurements are transmitted to the PSC software. Optimal trims determined by PSC are sent to the engine and inlet.

Figure 4 shows the three major algorithm components. These components consist of the identification, integrated system-modeling, and optimization blocks. Detailed descriptions of the PSC algorithm have been reported $^{1,3,6}$, so only selected aspects are briefly described in the following subsections.

\section{Identifying Component Deviation Parameters}

A Kalman filter $(\mathrm{Kf})$ provides real-time algorithm adaptability for off-nominal engine performance. This filter identifies component deviation parameters characterizing off-nominal engine performance. These parameters are then transmitted to the integrated system model. Component deviation parameters are used to update the model to more closely match operation of the engine. ${ }^{10}$ This adaptive feature permits optimization of any F100 engine, regardless of the state of degradation.

\section{Modeling the Engine and Inlet}

The integrated system model consists of simplified steady-state models for the engine and inlet. These models combine measurements with $\mathrm{Kf}$ estimates to periodically determine the state and performance of the propulsion system. These compact models also compute propulsion system parameters which are not directly measurable, such as nozzle exhaust temperature, fan stall margin, percentage of critical mass flow, and net propulsive force $(F N P)^{2,6}$ The integrated system model generates a linear airframe and propulsion system representation of the operating point. This linearized model is needed by the optimization logic to determine system sensitivities to control inputs.

Within the algorithm, control variables are perturbed by the optimization logic until convergence is achieved. These variables are input to the integrated system model to determine airframe and propulsion system sensitivities. An optimal control trim set is then determined on the basis of modeled sensitivities, constraints, and performance index and sent to the actual inlet and engine. After convegence, optimal trim commands are applied to the real propulsion system on the basis of a modeled local optimum.

\section{Optimizing the Integrated System Model}

The optimization logic employs a linear programming technique to optimize the integrated system model. Minimum fuel, maximum thrust, and minimum FTIT each have a characteristic performance index and equality constraint. The performance index of the three modes is total engine fuel flow, $F N P$, and $F T I T$, respectively. Minimum fuel and minimum FTIT modes are constrained to a constant condition where the thrust level should remain unaffected by the optimization, but the maximum thrust mode has no equality constraint.

Minimum fuel is the only optimization mode which directly controls $W F A B$. In general, the $\mathrm{A} / \mathrm{B}$ is much less efficient at converting fuel flow to thrust than is the engine core. As such for a given thrust level, producing as much of the thrust as possible from the more efficient core is advantageous because it reduces the $\mathrm{A} / \mathrm{B}$ thrust requirements. By trimming closer to such operating limits as fan stall margin than the standard F100 DEEC control logic, the PSC logic increases the amount of thrust generated by the core. This action, in turn, allows the thrust, and hence fuel flow, requirements of the $\mathrm{A} / \mathrm{B}$ to be reduced. The amount of $W F A B$ that may be reduced is effectively determined by

$$
\triangle W F A B=-\frac{(\partial F N P / \partial W F)}{(\partial F N P / \partial W F A B)} \Delta W F
$$

The ratio of the partial derivatives is a measure of the relative efficiencies of the core and the augmenter to convert fuel flow to $F N P$. The $\partial F N P / \partial W F$ is approximately two to three times greater than $\partial F N P / \partial W F A B$. 
The three modes are also subject to designed system constraints. Most PSC constraints fall into two categories: physical boundaries and stability margins. Both constraints limit commanded trims for such controls as engine and inlet variable-geometry control effectors and fuel flows. The first category is typified by the movement of the engine variable vanes and inlet ramps. Such movements are limited to a maximum and minimum determined by physical stops. Stability margins affect control indirectly through DEEC or PSC logic. For example, if PSC or DEEC logic determines that the requested EPR trim will cause a fan stall, then the EPR trim is limited to some maximum value.

Similar to the engine, the inlet has stability margins. Shock displacement ratio $(S D R)$ and percent inlet critical mass flow $(P C T C)$ are two such stability margins. The $S D R$ is the perpendicular distance of the nearest oblique shock to the cowl lip. For stable operation, $S D R$ must remain positive; otherwise, the inlet will ingest the shock and produce high distortion at the inlet face. The PCTC is the ratio of the inlet mass flow to the critical mass flow at which the throat Mach number is 1 and beyond which the normal shock is ingested. ${ }^{7}$

\section{Determining the Net Propulsive Force}

Note that the optimization is performed on a modelgenerated airframe and propulsion system and that thrust, a key parameter required for each mode, is not a measured feedback in this control structure. Instead, the integrated system model estimates thrust, or $F N P$, and many other parameters on the basis of control positions and other measured and calculated parameters. For PSC, FNP is defined as

$$
F N P=F N-D N O Z-D I N L T-D T R I M
$$

where $F N$ is the installed net thrust, $D N O Z$ is the incremental nozzle drag, DINLT is the incremental inlet spillage drag, and DTRIM is the incremental trim drag for the cowl and stabilator.

Figure 5 shows the longitudinal aircraft forces as modeled by PSC. The $D N O Z$ accounts for the drag associated with off-reference nozzle and plume configuration. The DINLT accounts for off-reference inlet airflow at off-scheduled cowl position. If the inlet is trimmed to an off-scheduled position, then an incremental lift is produced, thus imparting a pitching moment on the airframe. To offset the pitching moment and maintain level fight, the stabilator is repositioned to produce a counteracting pitching moment; however, stabilator drag is also affected. The DTRIM accounts for the incremental stabilator trim drag and the incremental inlet drag associated with moving the cowl offschedule. Note that DTRIM is the only airframe term contained within the PSC logic and that it is modeled.
In addition, the stabilator is not directly controlled by PSC, but rather it depends on the autopilot or pilot to trim the pitching moments.

The optimal solution for any of the three modes depends on an accurate model-based calculation of $F N P$. Without a feedback measurement of thrust and without perfect models, a physical optimum operating point cannot be achieved. Nonetheless, thrust stand tests indicate the PSC $F N$ estimate to be within 2 to 3 percent and exceptionally adept at tracking trends. ${ }^{5}$

\section{Comparing the Supersonic and Subsonic Algorithms}

In addition to the task required for subsonic operation ${ }^{1,3,6}$, the PSC integrates the inlet variable ramps and operates the $A / B$. Both subsonic and supersonic algorithms contained an inlet model to determine inlet spill drag and pressure recovery; however with supersonic operation, the model must estimate shock locations, critical mass flow, and integrated effects of the incremental stabilator trim drag. The subsonic and supersonic schemes also included an $\mathrm{A} / \mathrm{B}$ in the models, but the $A / B$ is seldom used in the steady-state subsonic envelope. The A/B adds complexity to the supersonic algorithm because of its important role in calculating FNP.

All supersonic testing occurred at power settings that included engine $A / B$ operation. Hence, total engine fuel flow consists of $W F+W F A B$. The $W F$ remains essentially continuous with power setting; whereas, the $W F A B$ is characterized by discrete numbers of segments lighting as a function of power setting and flight condition. The 16 segments in the $A / B$ are controlled by a sequencing valve. Switching segments results in a discrete jump in total augmenter fuel flow. Each segment has additional fine-tuning control of fuel flow which helps to minimize the discontinuity when switching between segments.

\section{Flight Test Program}

The initial supersonic PSC flight test program was conducted at the DFRF during 1992. Objectives of the initial supersonic flight test series included algorithm validation and preliminary baseline algorithm evaluation. To date, flight testing has consisted of evaluating a single engine and inlet in one PSC mode at any given time. No provision existed for testing the left and right propulsion systems simultaneously. One-engine testing was not a disadvantage because most PSC system benefits are on a per engine basis.

Preliminary baseline algorithm flight testing consisted of cruise tests to quantitatively assess the PSC steady-state performance improvements. To allow for later comparisons, procedures were designed to 
minimize the effect of outside influences. For the majority of the points, flight condition was maintained using altitude-hold and adjusting the nontest engine power setting. Because of limitations on available fuel and supersonic airspace restrictions, test maneuvers were limited to $2 \mathrm{~min}$, and some points were not repeated.

Baseline testing consisted of tests for all three modes at afterburning power settings with the inlet and stabilator included in the optimization algorithm. A limited amount of flight test data were collected at the primary supersonic conditions listed in table 1 . A 25,000$\mathrm{ft}$ condition was chosen because predicted benefits were high for all three modes. At an altitude of $45,000 \mathrm{ft}$, subsonic PSC achieved its best performance improvements. To determine if similar results were achievable supersonically at an altitude of $45,000 \mathrm{ft}$, supersonic PSC was also evaluated.

As an independent assessment of the effect of airframe integration, a parametric study was conducted to determine the effect of optimizing the inlet and stabilator on PSC performance. Testing consisted of one continuous cruise beginning with the inlet and stabilator optimized. This cruise was followed immediately without optimizing the inlet and stabilator. The procedure was designed to emphasize maintaining conditions and to permit a direct comparison of the two runs.

\section{Results and Discussion}

Test results of using the minimum fuel, maximum thrust, and minimum FTIT optimization modes of the PSC system are discussed in the following subsections. The maneuvers were designed to evaluate PSC system operation and overall performance benefits. These flight data were obtained from the right engine and inlet during cruise tests.

\section{Minimum Fuel Mode}

By controlling stabilator, nozzle, inlet and engine geometries, and fuel flow, the minimum fuel mode minimizes total engine fuel flow while maintaining constant $F N P$. In effect, this mode minimizes thrust specific fuel consumption $(T S F C)$. The minimum fuel mode was successfully tested at $110^{\circ}$ power lever angle, or midafterburning.

Figures 6(a) and (b) show results from a cruise test at Mach 1.25 and at an altitude of $25,000 \mathrm{ft}$. Mach number was maintained within \pm 0.005 for the duration of the test. Time histories are given for the $W F$, $A J, C I V V, R C V V$, cowl, ramp, and $W F A B$ engine and inlet control variables; TSFC, FNP, and FTIT algorithm performance variables; EPR; and fan airflow (WCFAN). The EPR is defined as PT6/PT2, where $P T 6$ is the augmenter inlet total pressure, and $P T 2$ is the total pressure at the engine face. The PSC algorithm was engaged at $47 \mathrm{sec}$ into the test run. Both $F N P$ and $W F$ converged at approximately $87 \mathrm{sec}$, or $40 \mathrm{sec}$, after PSC engagement. Thus, steady-state results pertain to the last part of the maneuver, where measured parameters are less transient. Steady-state value of $T S F C$ with PSC engaged was approximately 1.79. The steady-state value for the baseline configuration was 1.96 . This value was substantially greater than the one with PSC on, and it resulted in an 8.4 percent decrease in $T S F C$ with PSC. After engaging PSC, steady-state $F N P$ lost approximately 1 percent, within the targeted PSC bounds of \pm 2 percent.

The decrease in $T S F C$ was achieved because of a decrease in total engine fuel flow and an increase in $F T I T$. The $F N$ generated from the core is a function of EPR, WCFAN, and $W F$. An increase in any of these parameters while holding the other parameter constant increases core $F N$. Figures 6(a) and (b) show that an increase in all three parameters indicates a large increase in core thrust. Simultaneously, $W F A B$ decreased by approximately $2000 \mathrm{pph}$, indicating a loss of A/B-produced $F N$. Note that as a side effect of trading A/B for $W F, F T I T$ is driven to its maximum limit of $2300^{\circ} \mathrm{R}$. Such a temperature increase reduces engine life.

Immediately after completing the portion of the test which required optimizing the inlet and stabilator, PSC was evaluated without optimizing the inlet and stabilator. The flight condition remained Mach 1.25 at an altitude of $25,000 \mathrm{ft}$, and Mach number was maintained within \pm 0.005 .

Figures 7(a) and (b) show time histories for the portion of the test conducted without optimizing the inlet and stabilator. As with the minimum fuel mode with the inlet optimized, $W F A B$ is traded for $W F$ to reduce total engine fuel flow. The $C I V V$ never stabilized but almost reached its physical limit of $7^{\circ}$. Except for the $C I V V$, the engine control variables reached steady state during the last part of the maneuver. The steadystate value of $T S F C$ with PSC on was approximately 1.81. For the nominal engine, $T S F C$ was 1.97 , substantially greater than with PSC on. The PSC achieved a 7.9 percent decrease in TSFC without optimizing the inlet and stabilator. During PSC operation, steadystate $F N P$ was 2.2 percent less than without PSC optimization, slightly larger than the targeted PSC bounds of \pm 2 percent.

In both test cases, FNP was lost; therefore, the estimated TSFC benefits maybe somewhat optimistic because additional thrust should have been applied. This steady-state thrust drop-off also indicates a fundamental weakness of the model-based 
approach: No means exist to eliminate steady-state errors in the thrust constraint.

Overall, the performance results are essentially identical for the two cases, thus indicating that inclusion of an optimized inlet and stabilator is not very significant. Instead, the majority of $T S F C$ savings results from the tradeoff between $W F$ and $W F A B$. For either case, the $T S F C$ savings of approximately 8 percent produced by PSC are very significant.

\section{Maximum Thrust Mode}

The maximum thrust mode aims to maximize the combined engine and airframe $F N P$ by controlling the stabilator, the nozzle, the fuel flow, and the inlet and engine geometries. This mode was successfully tested at the flight conditions listed in table 2. Except for the Mach 1.50 at altitude of $30,000-\mathrm{ft}$ condition, the ramp signal was not recorded because of instrumentation problems.

The optimal combination of increased $F N$ and reduced drag will yield the maximum thrust. When operating with the $A / B$, the maximum thrust mode was designed to operate only at the maximum $A / B$ setting. At this setting, the maximum $W F A B$ is delivered, so $W F A B$ is not included in the optimization as a control. For this reason, $F N$ increases resulting from the maximum thrust mode will primarily be generated from the core section.

Figures 8(a) and (b) show the results of the cruise test at Mach 1.25 and at an altitude of 25,000 ft. Mach number was held within \pm 0.005 for the entirety of the test. Time histories are given for the $W F, A J, C I V V$, $R C V V$, cowl, and $W F A B$ engine and inlet control variables; TSFC, FNP, and FTIT algorithm performance variables; EPR; and $W C F A N$. The PSC was engaged from $36 \mathrm{sec}$ to after initial steady-state operation. The $F N P$ converged at approximately $65 \mathrm{sec}$. Thus, steady-state results relate to the period after $65 \mathrm{sec}$. The steady-state value of FNP without using PSC was approximately 18,600 lbf. Use of PSC increased $F N P$ to $20,250 \mathrm{lbf}$.

The PSC achieved a 9 percent increase in FNP. Although optimizing the PSC lead to increased FTIT and fuel flow, the PSC-optimized engine was more fuel efficient in the maximum thrust mode than the nominal engine. The TSFC was reduced by approximately 3 percent. Meanwhile, FTIT reached its limit, and total fuel flow increased by $2000 \mathrm{pph}$. The savings in $T S F C$ resulted from increased production of $F N$ by the more efficient core. The increase in FNP was achieved by nearly a 10-pps up-trim in WCFAN and by a modest increase in EPR from 2.45 to 2.75 . In addition, $W F A B$ increases by nearly $1000 \mathrm{pph}$ because of the baseline DEEC schedule.
When not optimizing the inlet and stabilator, the maximum thrust mode abtains approximately an 8.5 percent $F N P$ increase (Figs. 9(a) and (b)). As figure 9 (a) shows, all the controls are nearly identical to the case with inlet and stabilator except for the cowl. According to the models, the majority of $F N P$ increases results from large increases in $F N$, not from drag reductions (Fig. 10). As with the minimum fuel mode, contributions of including the inlet and stabilator in the optimization appear very small in the maximum thrust mode at this flight condition.

At 45,000-ft supersonic conditions, the baseline engine operates over the PSC FTIT limit of $2300^{\circ} \mathrm{R}$. As a result, the PSC optimization produced minimal increases in thrust, but it did bring FTIT down to within the $2300^{\circ} \mathrm{R}$ limit. At Mach 1.50 at an altitude of $30,000 \mathrm{ft}$, the maximum thrust mode produced promising results (about a 7.5 percent thrust increase); however, Mach number was not maintained because the test was designed to correlate $F N P$ with measured longitudinal acceleration.

\section{Minimum Fan Turbine Inlet Temperature Mode}

The minimum FTIT mode minimizes FTIT through optimal control of the variable-inlet and engine geometries, fuel flow, and stabilator while maintaining a constant FNP. The minimum FTIT mode was successfully tested at the flight conditions listed in table 3. Ramp was only recorded for the Mach 1.25 at an altitude of $25,000-\mathrm{ft}$ test.

The most effective way to reduce turbine temperature is by reducing $W F$. If $W F A B$ were included as a control for the minimum FTIT mode, as it is for the minimum fuel mode, then $W F$ would be traded for $W F A B$ to reduce $F T I T$. The $W F$ would decrease, and $W F A B$ would increase so as to maintain constant $F N P$. However, total engine fuel flow would increase because of the less efficient $A / B$, which is unacceptable, thus dictating that no direct $W F A B$ control be involved in the optimization. Therefore, the only way to reduce the required $F N$ while still maintaining $F N P$ is through drag reductions.

Figures 11(a) and (b) present time histories for a minimum FTIT cruise test at Mach 1.80 , at an altitude of $45,000 \mathrm{ft}$, and with a $116^{\circ}$ power lever angle, or midafterburner power setting. Although this test was conducted only once at this condition, results represent the minimum FT IT mode on the basis of predicted results and subsonic-testing experience. Mach number was held to within \pm 0.005 for the test. No test at this condition was available where the inlet and stabilator were not included in the optimization. Time histories are given for the $W F, A J, C I V V, R C V V$, cowl, and $W F A B$ engine and inlet control variables; 
$T S F C, F N P$, and FTIT algorithm performance variables; EPR; and WCF $A N$. After approximately $54 \mathrm{sec}$ of steady-state trim cruise condition, PSC was turned on. After the engine controls converged, steady-state results were reflected for from approximately $95 \mathrm{sec}$ to the end of the maneuver. With use of PSC, FTIT was reduced by $85^{\circ} \mathrm{R}$, and $F N P$ was maintained to within 1 percent of baseline engine operation. In addition, $T S F C$ was reduced by approximately 5.2 percent. The EPR decreased from 2.03 to 1.70 , and WCFAN was up-trimmed by 11 pps to produce the FTIT and $T S F C$ savings.

According to the PSC models, a combination of drag reductions reduced the required amount of $F N$ (Fig. 12). All three drag components of FNP were decreased and together produced over $670 \mathrm{lb}$ of drag savings. Together, DINLT and DTRIM, the two drag terms most affected by inlet optimization, indicate that the inlet and stabilator provided an approximately $370-\mathrm{lb}$ drag reduction.

With a $116^{\circ}$ partial $\mathrm{A} / \mathrm{B}$ power setting at Mach 1.60 at an altitude of $45,000 \mathrm{ft}, F T I T$ savings were approximately $12^{\circ} \mathrm{R}$, much less than at Mach 1.80 and the same altitude. At Mach 1.25 at an altitude of $25,000 \mathrm{ft}$, the minimum FTIT mode was tested in a maximum afterburning power setting. Results were encouraging; $85^{\circ} \mathrm{R}$ reductions in FTIT were observed along with a secondary benefit of an approximately 4 percent reduction in $T S F C$.

\section{Concluding Remarks}

Initial flight testing of performance seeking control (PSC) in the supersonic flight envelope was completed for an F-15 aircraft using one engine in the afterburning power settings. A quantitative assessment determined that the PSC algorithm performed as desired supersonically. At the limited flight conditions tested, the effect of including the inlet and stabilator in the PSC control set was almost negligible. The PSC logic improves propulsion cycle efficiency by trimming closer to such operating limits as fan stall margin or turbine temperature than is allowed by the standard engine control logic. Separate tests of the three PSC optimization modes revealed significant performance benefits. These modes include minimum fuel, maximum thrust, and minimum fan turbine inlet temperature. Tests of the minimum fuel and minimum fan turbine inlet temperature modes were performed at constant thrust.

The minimum fuel mode demonstrated fuel savings of approximately 8 percent while maintaining nominal thrust levels during a test at Mach 1.25 at an altitude of $25,000 \mathrm{ft}$. At this test condition, the fuel savings were achieved primarily by decreasing afterburner fuel flow while increasing core fuel flow. The core fuel flow was increased until the maximum fan turbine inlet temperature, $2300^{\circ} \mathrm{R}$, was reached. Further increases are predicted at Mach numbers above 1.25 by reducing trim drag.

The maximum thrust mode showed thrust increases of up to 9 percent but only when the fan turbine inlet was allowed to operate at temperatures which exceeded nominal. If the nominal fan turbine inlet temperature were near or exceeded the maximum limit of $2300^{\circ} \mathrm{R}$, then little or no thrust improvements occurred.

Temperature reductions of up to $85^{\circ} \mathrm{R}$ occurred for the minimum fan turbine inlet temperature mode. At the same time, improvements were noted in fuel efficiency, and nominal thrust levels were maintained. These temperature reductions primarily resulted from reduced trim drag.

The PSC technology concept has been demonstrated and can result in significant improvements to net propulsion system performance and indicates potential savings by including integrated airframe effects to achieve drag reductions. However, the PSC algorithm is model-based and cannot produce optimal solutions without perfect models. The next logical step in the development of integrated optimal control research is the inclusion of additional measurements and feedback controls on the basis of the PSC experience.

\section{References}

${ }^{1}$ Smith, R.H., Chisholm, J.D., and Stewart, J.F., "Optimizing Aircraft Performance With Adaptive, Integrated Flight/Propulsion Control," J. Engineering for Gas Turbines and Power, vol. 113, Jan. 1991, pp. 87-94. (See also ASME paper 90-GT-252, 1990.)

${ }^{2}$ Orme, John S. and Gilyard, Glenn B., Subsonic Flight Test Evaluation of a Propulsion System Parameter Estimation Process for the F100 Engine, NASA TM-4426, 1992.

${ }^{3}$ Gilyard, Glenn B. and Orme, John S., Subsonic Flight Test Evaluation of a Performance Seeking Control Algorithm on an F-15 Airplane, NASA TM-4400, 1992.

${ }^{4}$ Chisholm, J.D., "In-Flight Optimization of the Total Propulsion System," AIAA-92-3744, July 1992.

${ }^{5}$ Conners, Timothy R., Thrust Stand Evaluation of Engine Performance Improvement Algorithms in an F-15 Airplane, NASA TM-104252, 1992.

${ }^{6}$ Lambert, H.H., Gilyard, G.B., Chisholm, J.D., and Kerr, L.J., "Preliminary Flight Evaluation of an Engine Performance Optimization Algorithm," AIAA-91-1998, June 1991. 
${ }^{7}$ Nobbs, S.G., Jacobs, S.W., and Donahue, D.J., "Development of the Full-Envelope Performance Seeking Control Algorithm," AIAA-92-3748, July 1992.

${ }^{8}$ Myers, Lawrence P. and Burcham, Frank W., Jr., Preliminary Flight Test Results of the F100 EMD Engine in an F-15 Airplane, NASA TM-85902, 1984.

${ }^{9}$ Burcham, Frank W., Jr., Myers, Lawrence P., and Walsh, Kevin R., Flight Evaluation Results for a Digital Electronic Engine Control in an F-15 Airplane, NASA TM-84918, 1983.

${ }^{10}$ Luppold, R.H., Roman, J.R., Gallops, G.W., and Kerr, L.J., "Estimating In-Flight Engine Performance Variations Using Kalman Filter Concepts," AIAA-892584, July 1989.
Table 2. Maximum thrust mode flight conditions.

\begin{tabular}{cc}
\hline Mach number & Altitude, $\mathrm{ft}$ \\
\hline 1.25 & 25,000 \\
1.50 & 30,000 \\
1.60 & 45,000 \\
2.00 & 45,000 \\
\hline \hline
\end{tabular}

Table 3. Minimum fan turbine inlet temperature mode flight conditions.

\begin{tabular}{cc}
\hline \hline Mach number & Altitude, $\mathrm{ft}$ \\
\hline 1.25 & 25,000 \\
1.60 & 45,000 \\
1.80 & 45,000 \\
\hline \hline
\end{tabular}

Table 1. Primary supersonic flight conditions.

\begin{tabular}{cc}
\hline \hline Mach number & Altitude, $\mathrm{ft}$ \\
\hline 1.25 & 25,000 \\
1.60 & 45,000 \\
2.00 & 45,000 \\
\hline
\end{tabular}

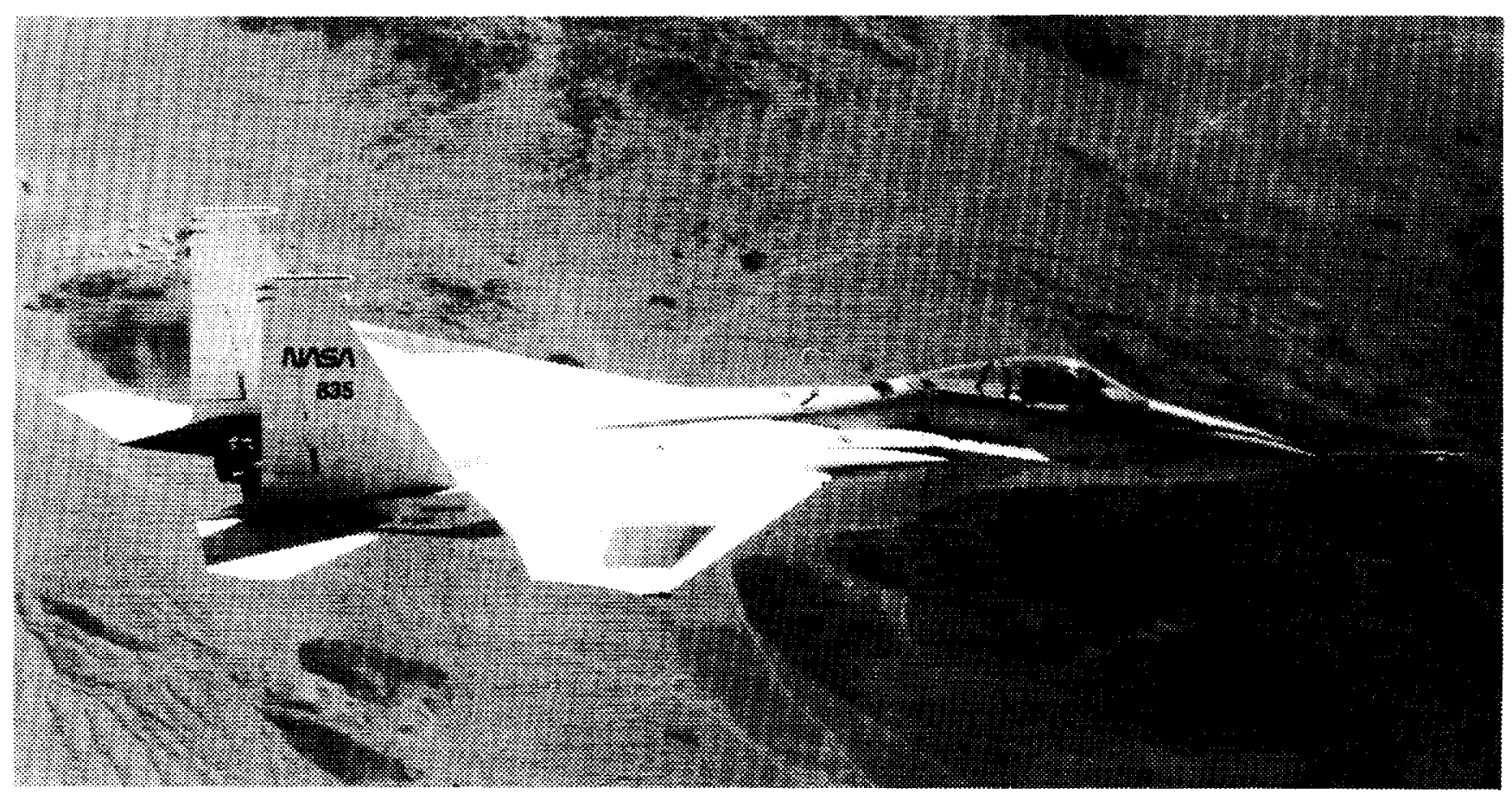

Fig. 1 The F-15 highly integrated digital electronic control aircraft. 


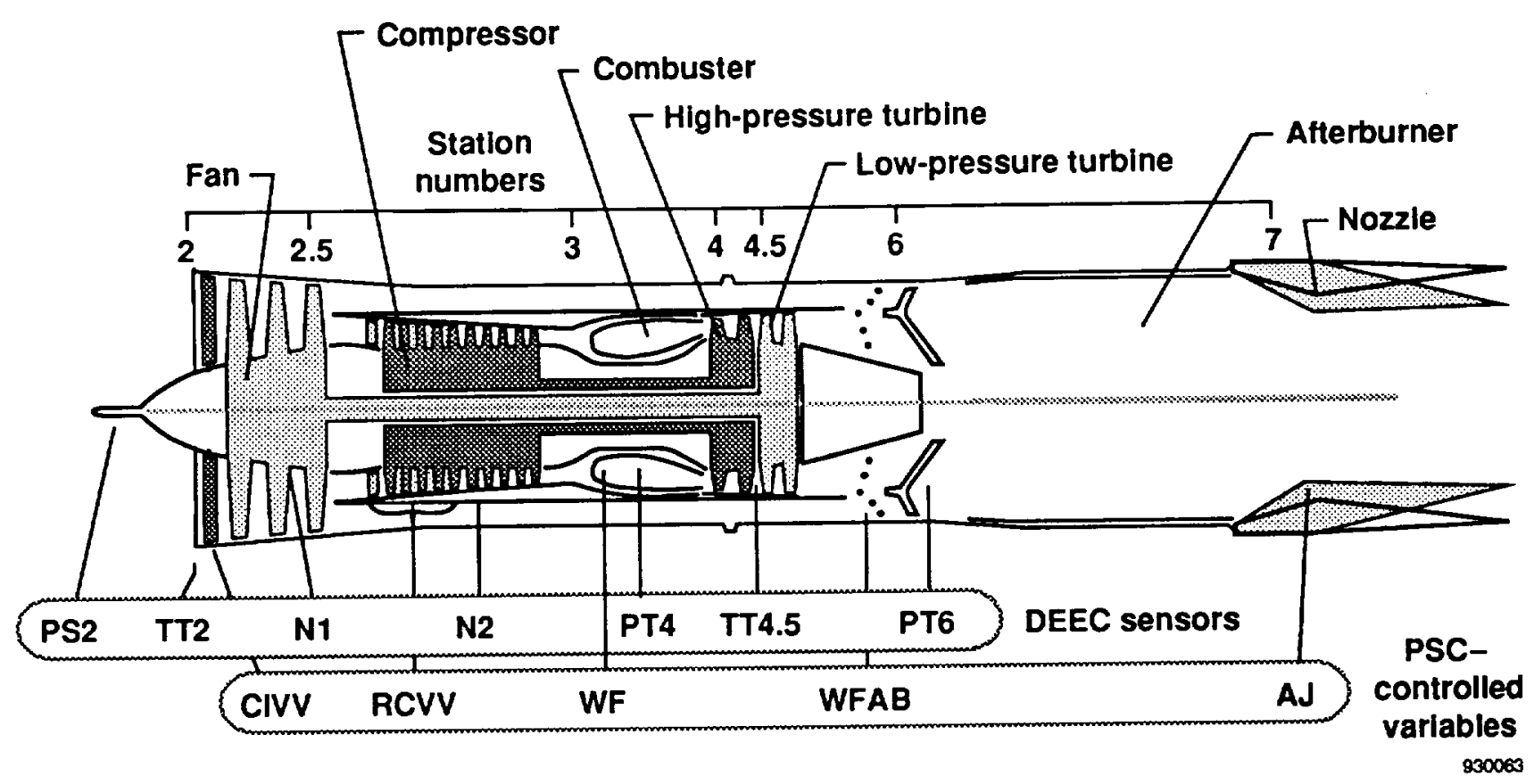

Fig. 2 The F100 engine with digital electronic engine control.
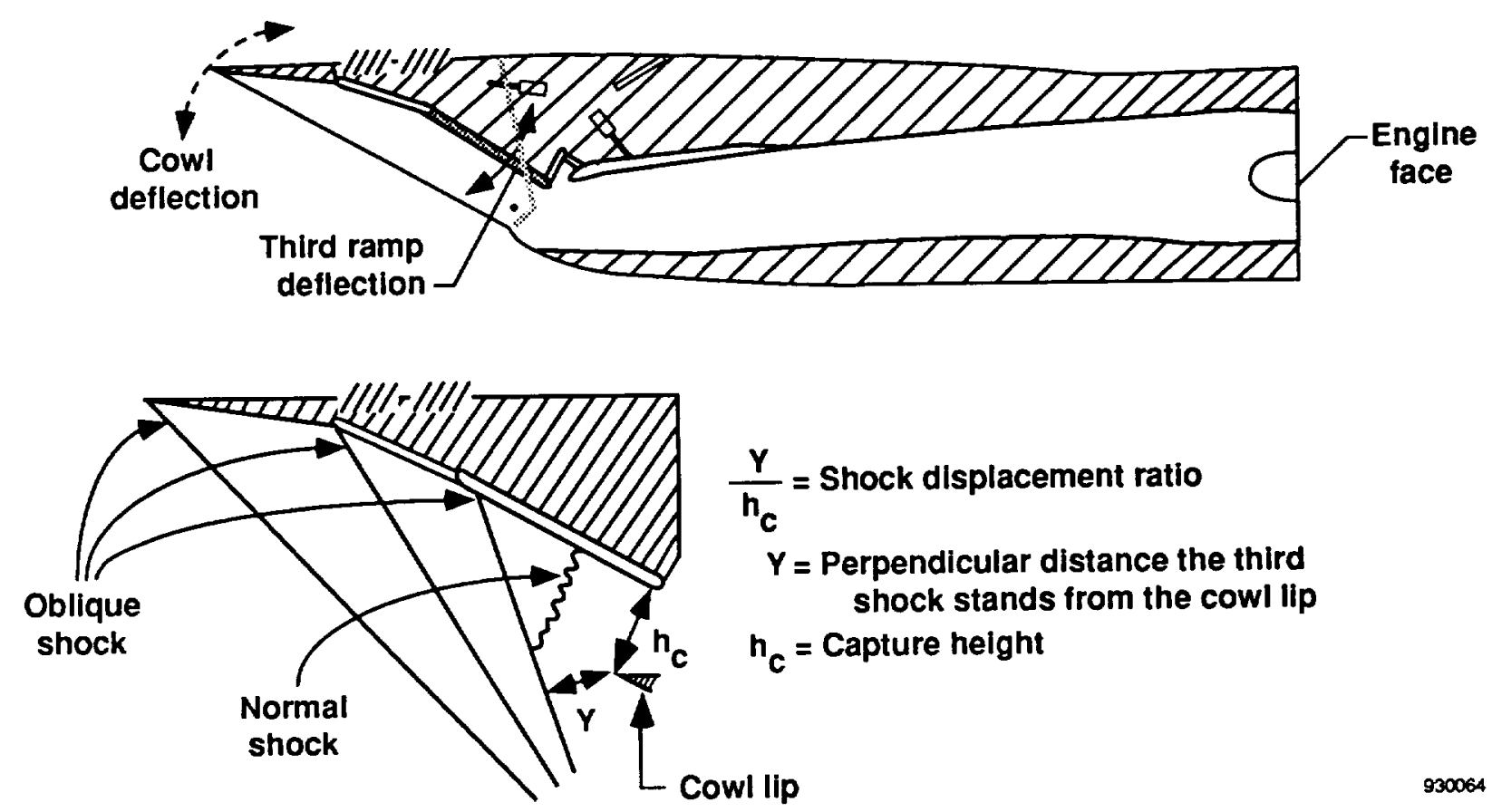

Fig. 3 The F-15 inlet (side view). 


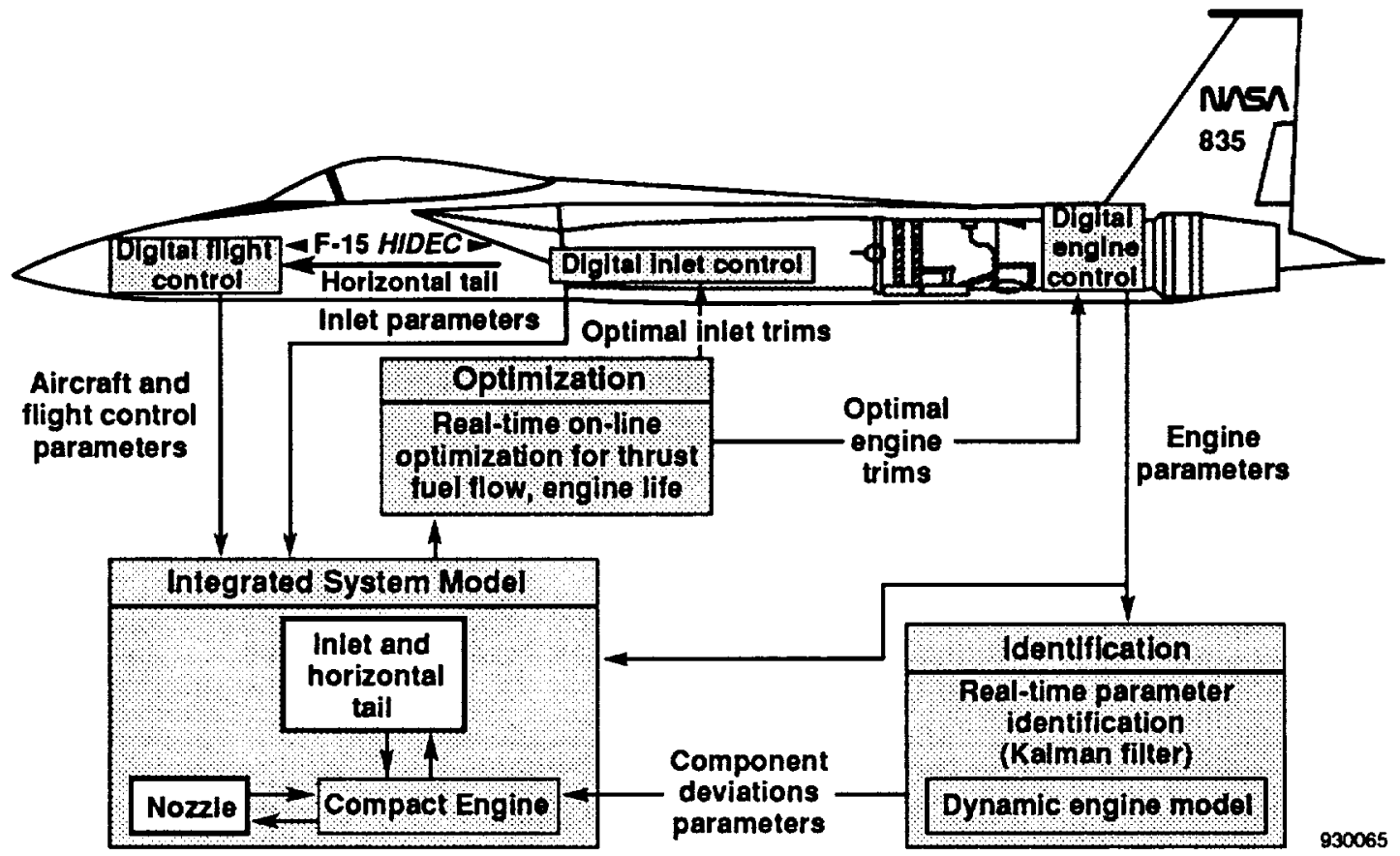

Fig. 4 Onboard, real-time optimization using the performance seeking control system.

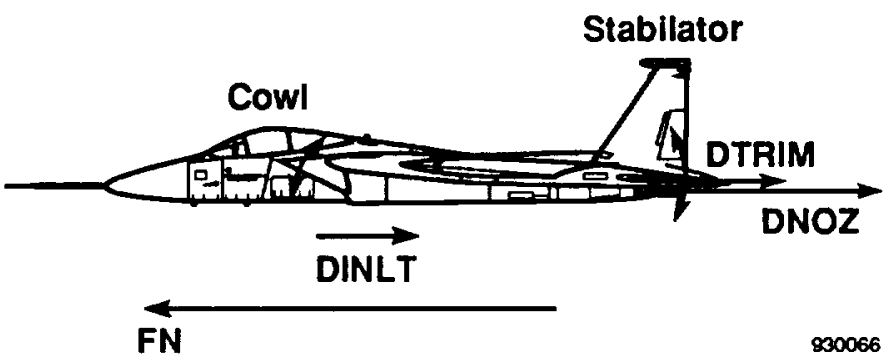

Fig. 5 Longitudinal aircraft forces. 


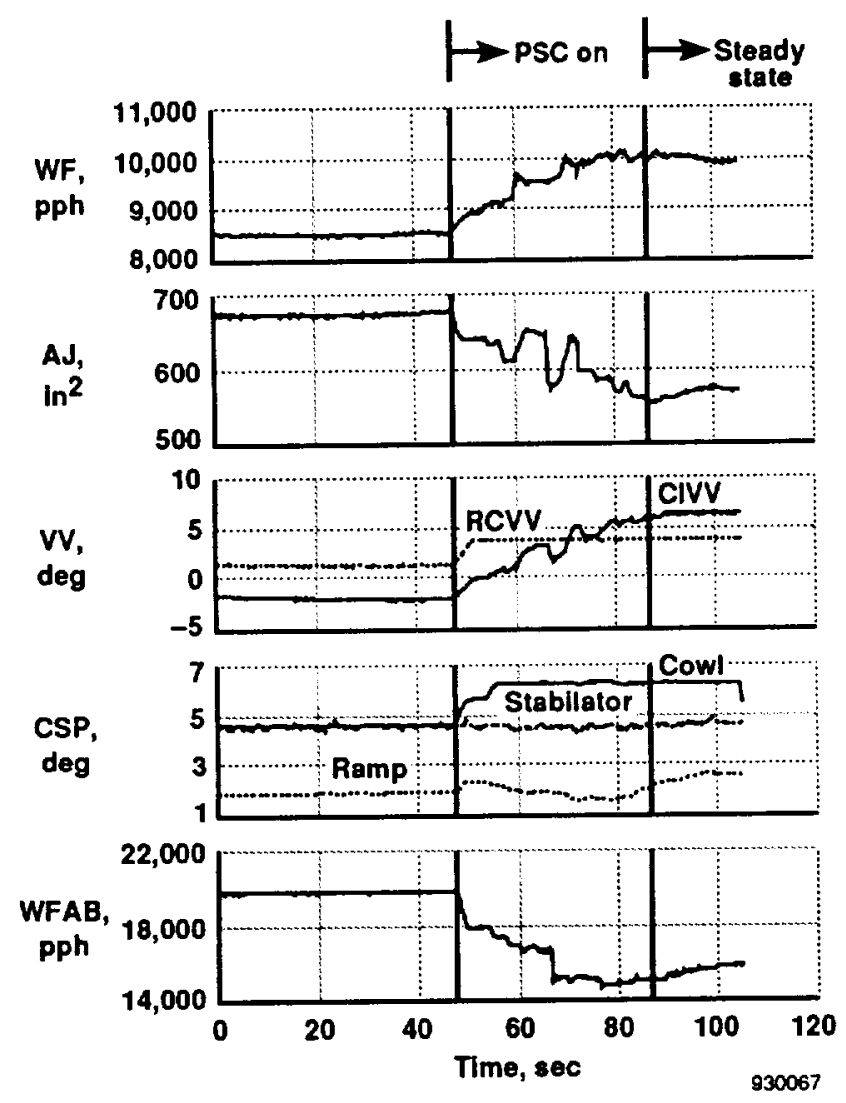

(a) Control variables.

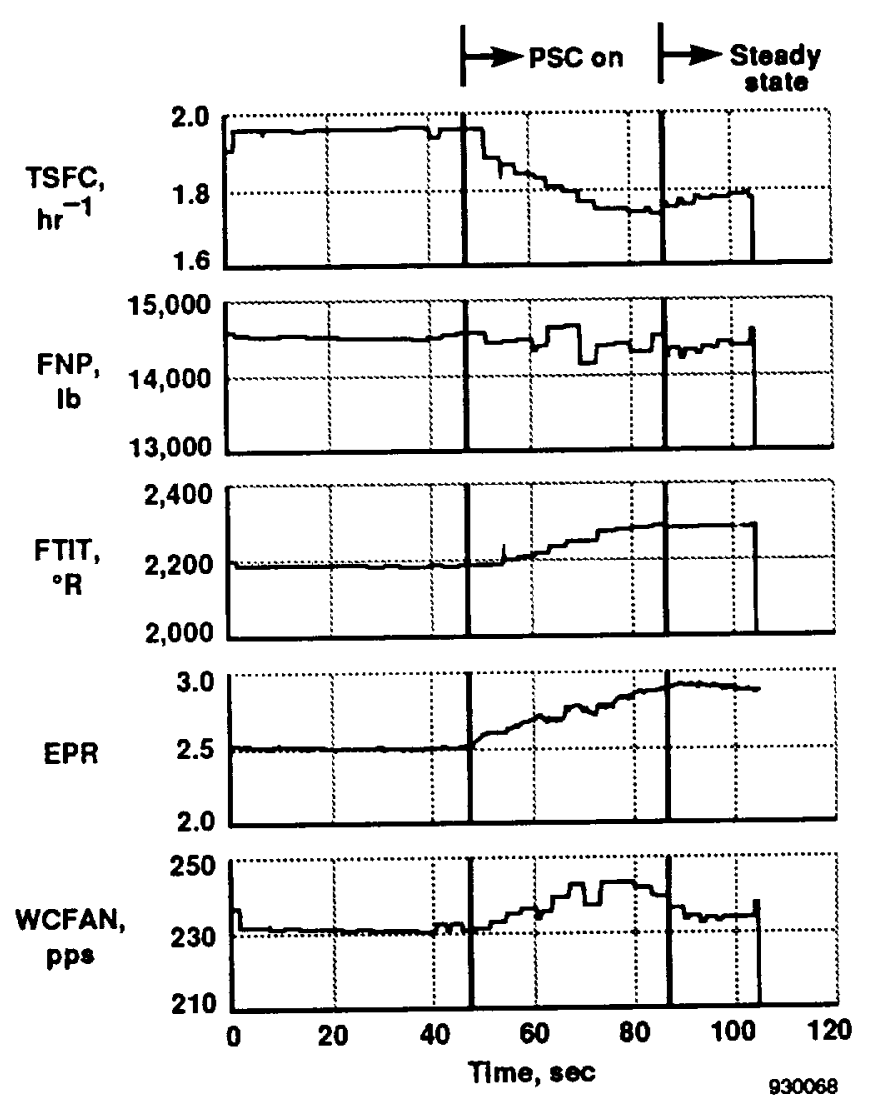

(b) Performance variables.

Fig. 6 Minimum fuel mode with inlet and stabilator optimization, at Mach 1.25, at an altitude of 25,000 ft, and with a $110^{\circ}$ power setting. 


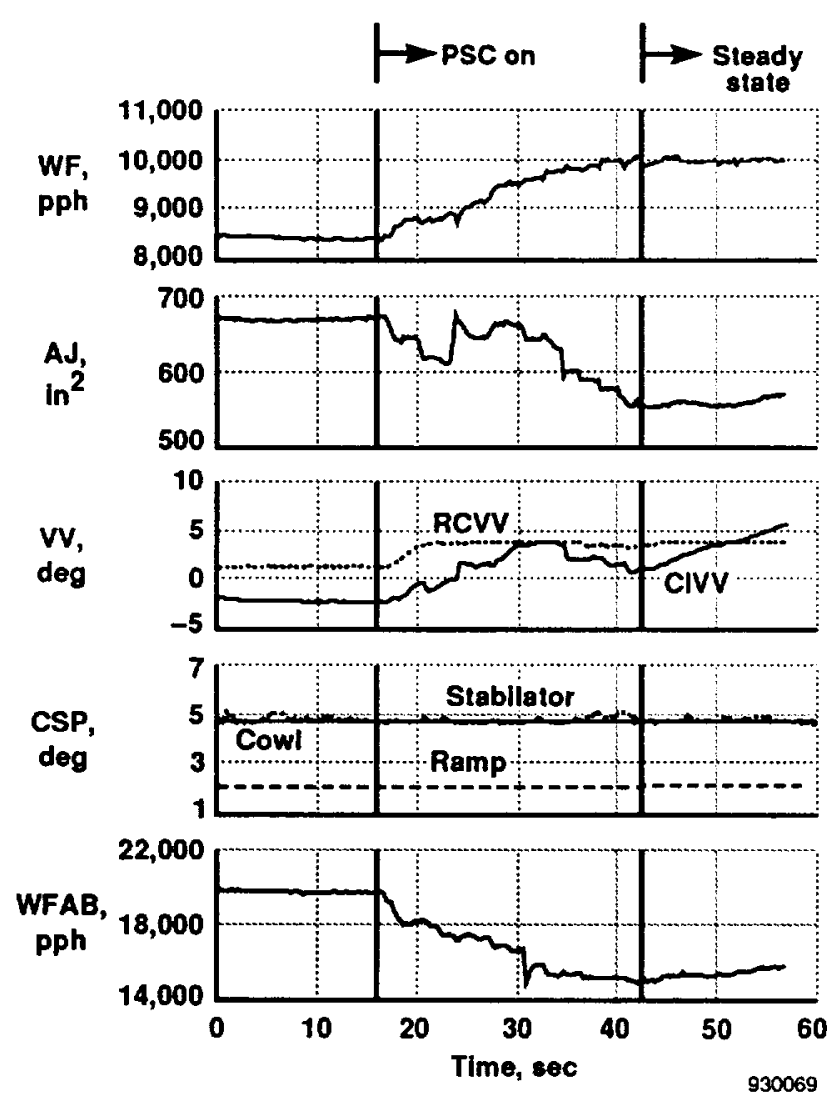

(a) Control variables.

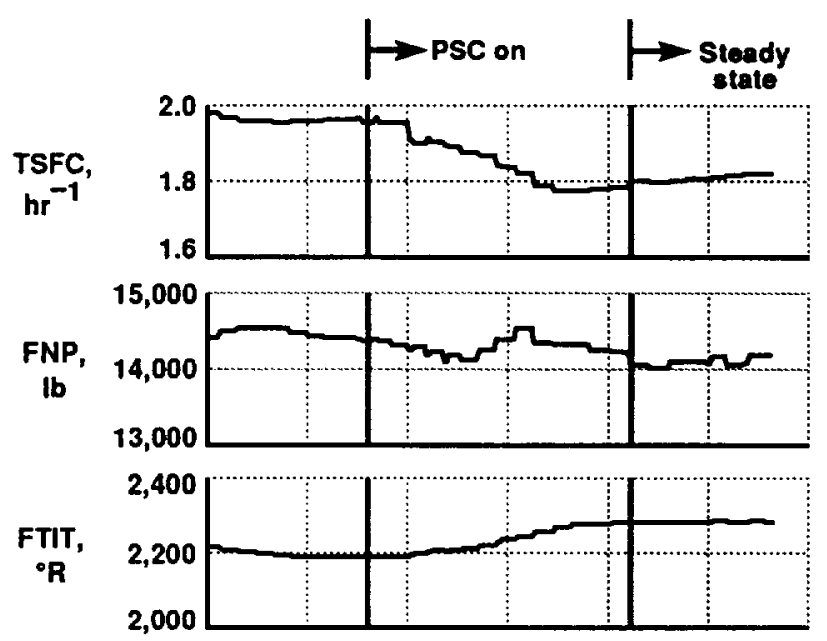

EPR
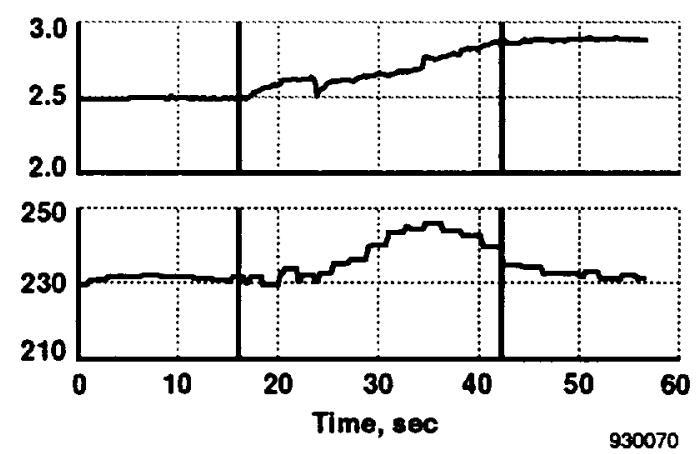

(b) Performance variables.

Fig. 7 Minimum fuel mode without inlet and stabilator optimization, at Mach 1.25, at an altitude of $25,000 \mathrm{ft}$, and with a $110^{\circ}$ power setting. 


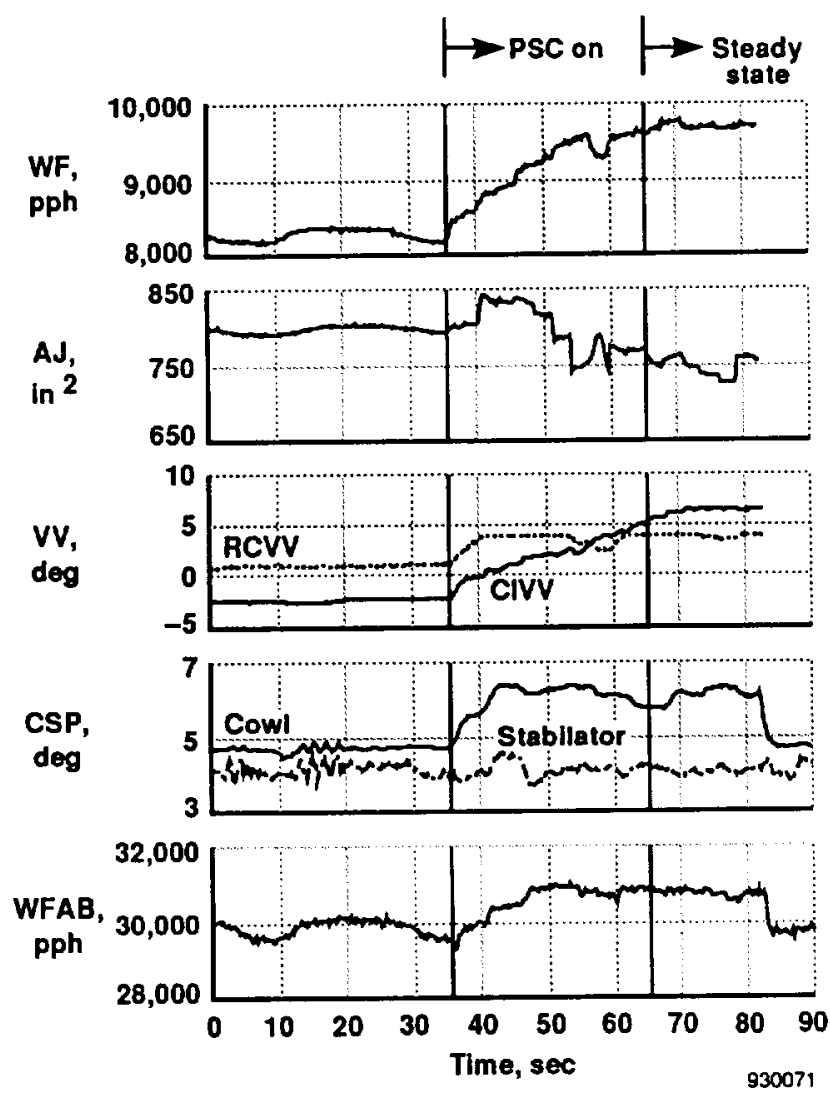

(a) Control variables.

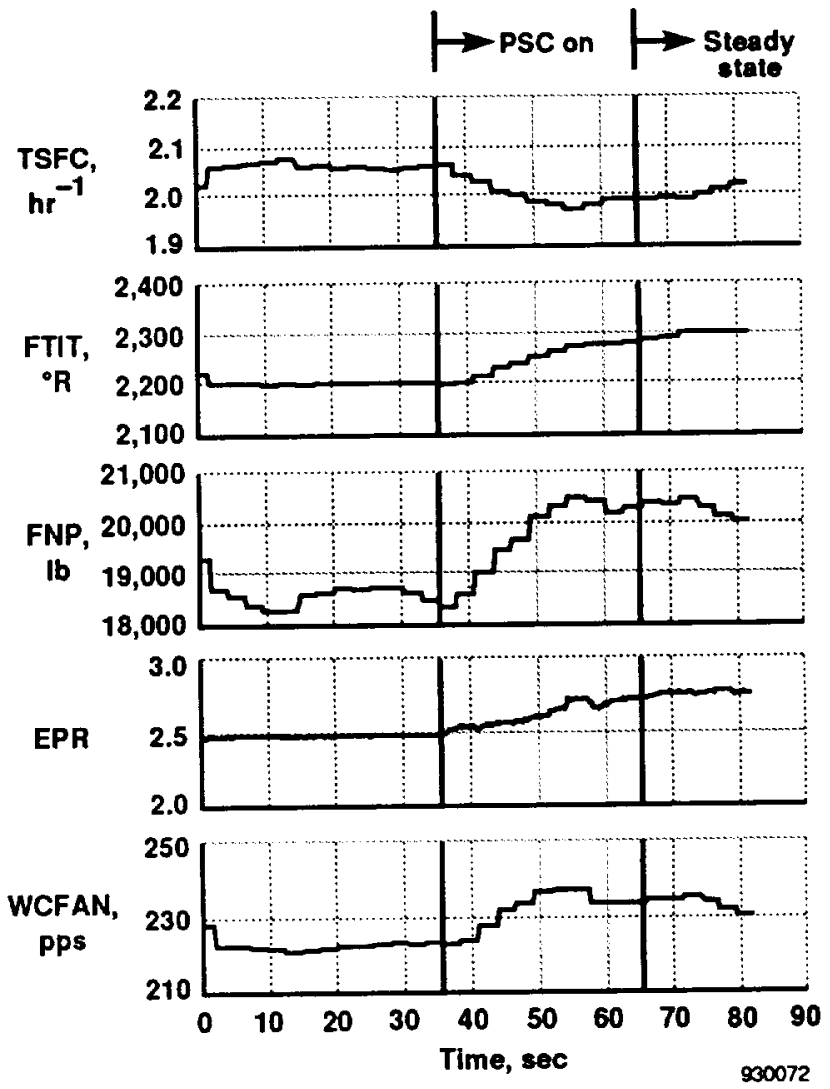

(b) Performance variables.

Fig. 8 Maximum thrust mode with inlet and stabilator optimization, at Mach 1.25, at an altitude of 25,000 ft, and with maximum afterburner power setting. 


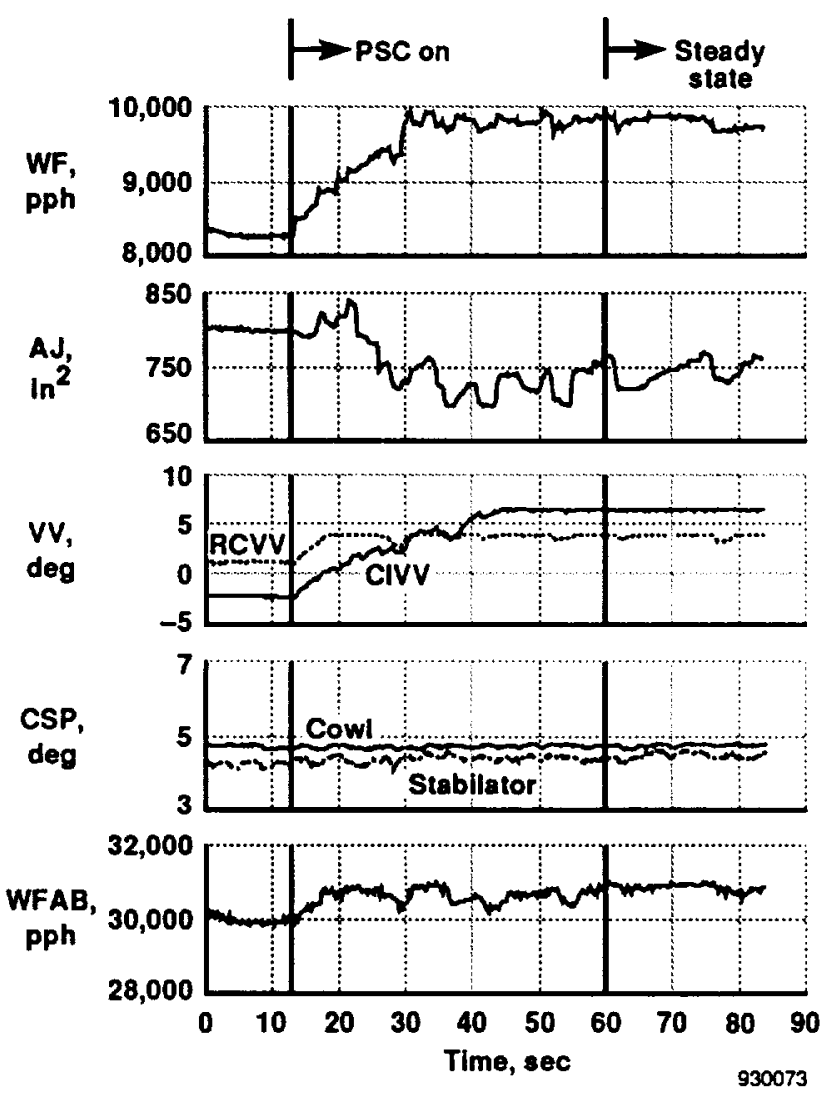

(a) Control variables.

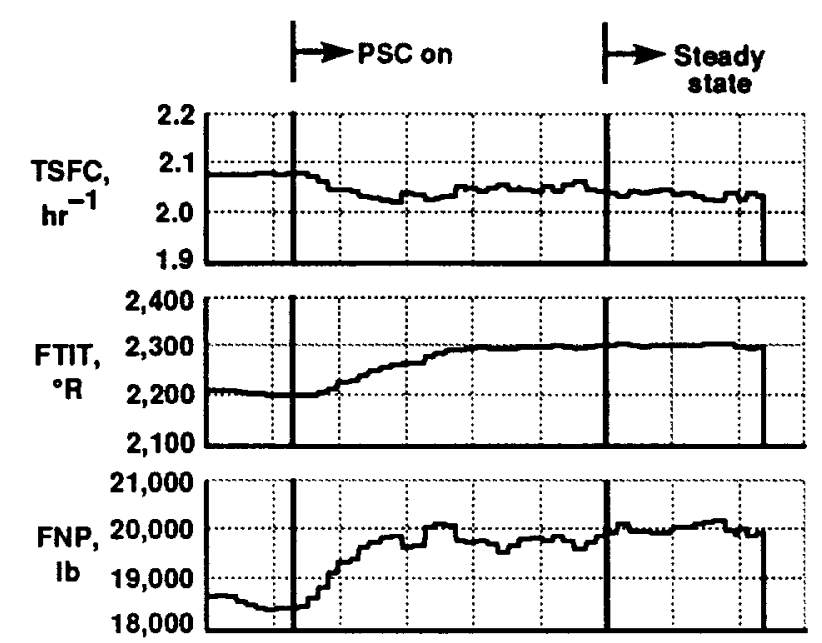

EPR

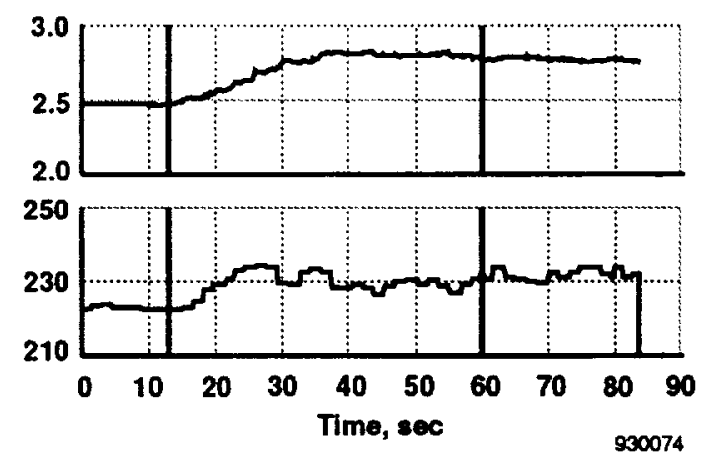

(b) Performance variables.

Fig. 9 Maximum thrust mode without inlet and stabilator optimization, at Mach 1.25, at an altitude of 25,000 ft, and with maximum afterburner power setting. 

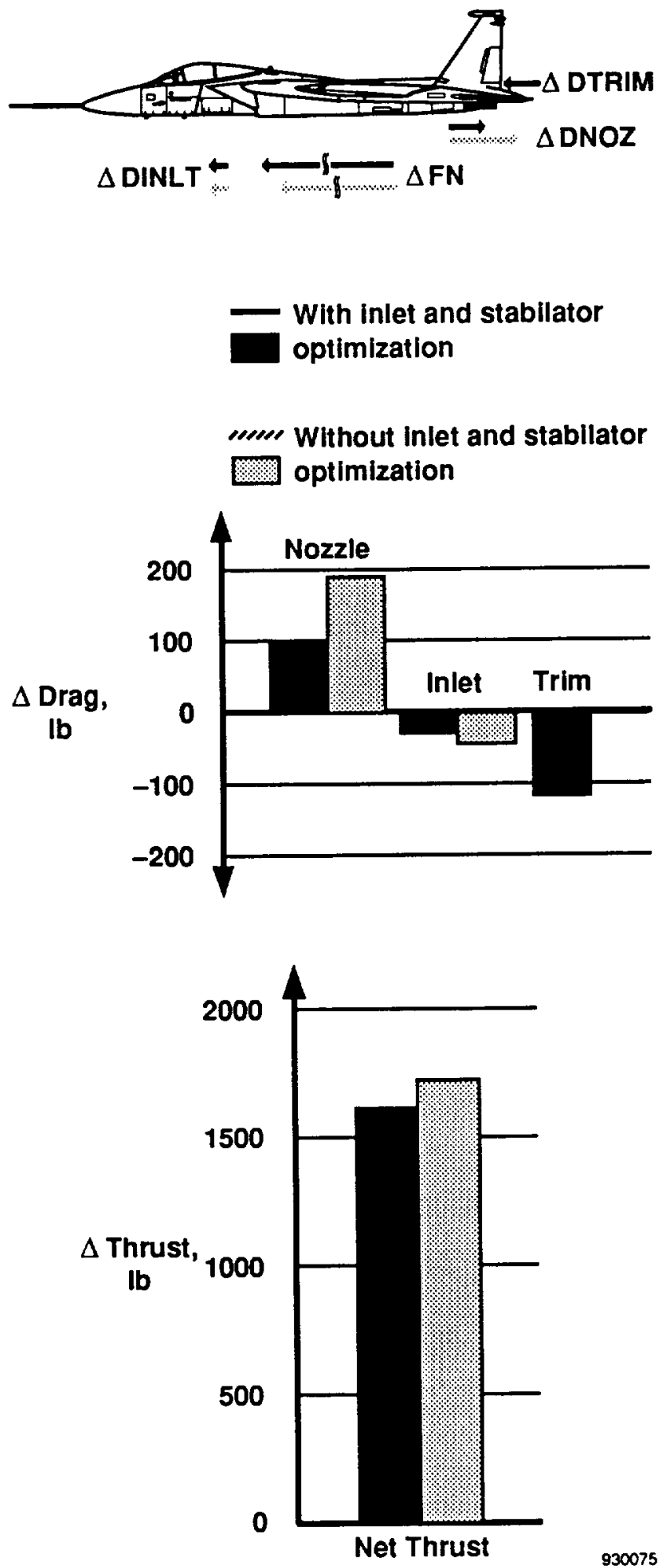

Fig. 10 Longitudinal aircraft forces for the maximum thrust mode with and without optimizing the inlet and stabilator, at Mach 1.25 , at an altitude of $25,000 \mathrm{ft}$, and with maximum afterburner power setting. 


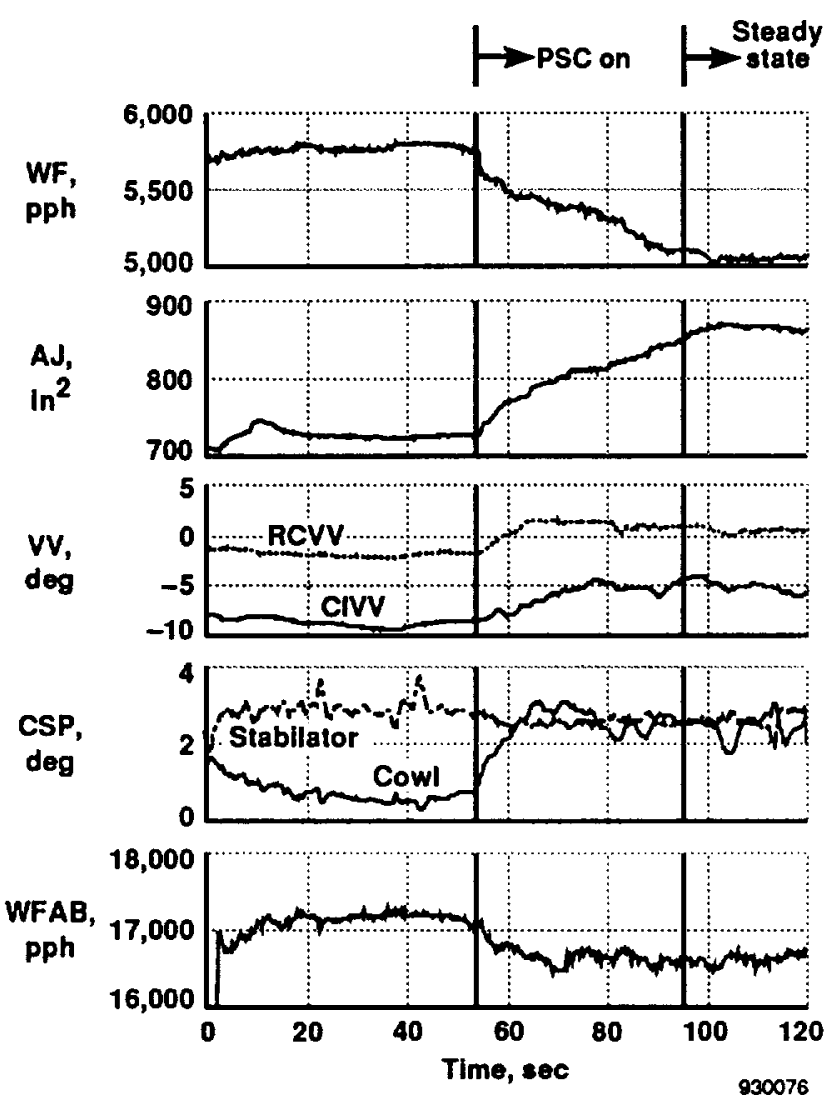

(a) Control variables.

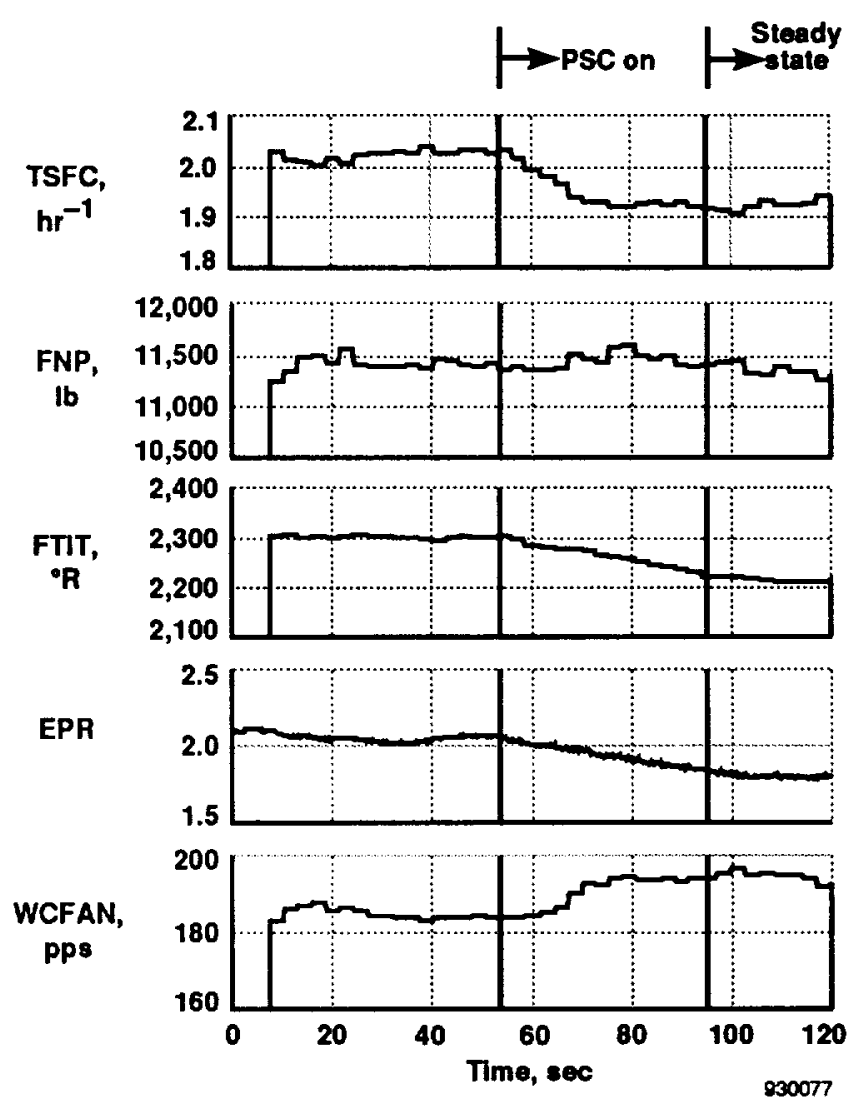

(b) Performance variables.

Fig. 11 Minimum fan turbine inlet temperature mode with inlet and stabilator optimization, at Mach 1.80, at an altitude of $45,000 \mathrm{ft}$, and with $116^{\circ}$ power setting. 

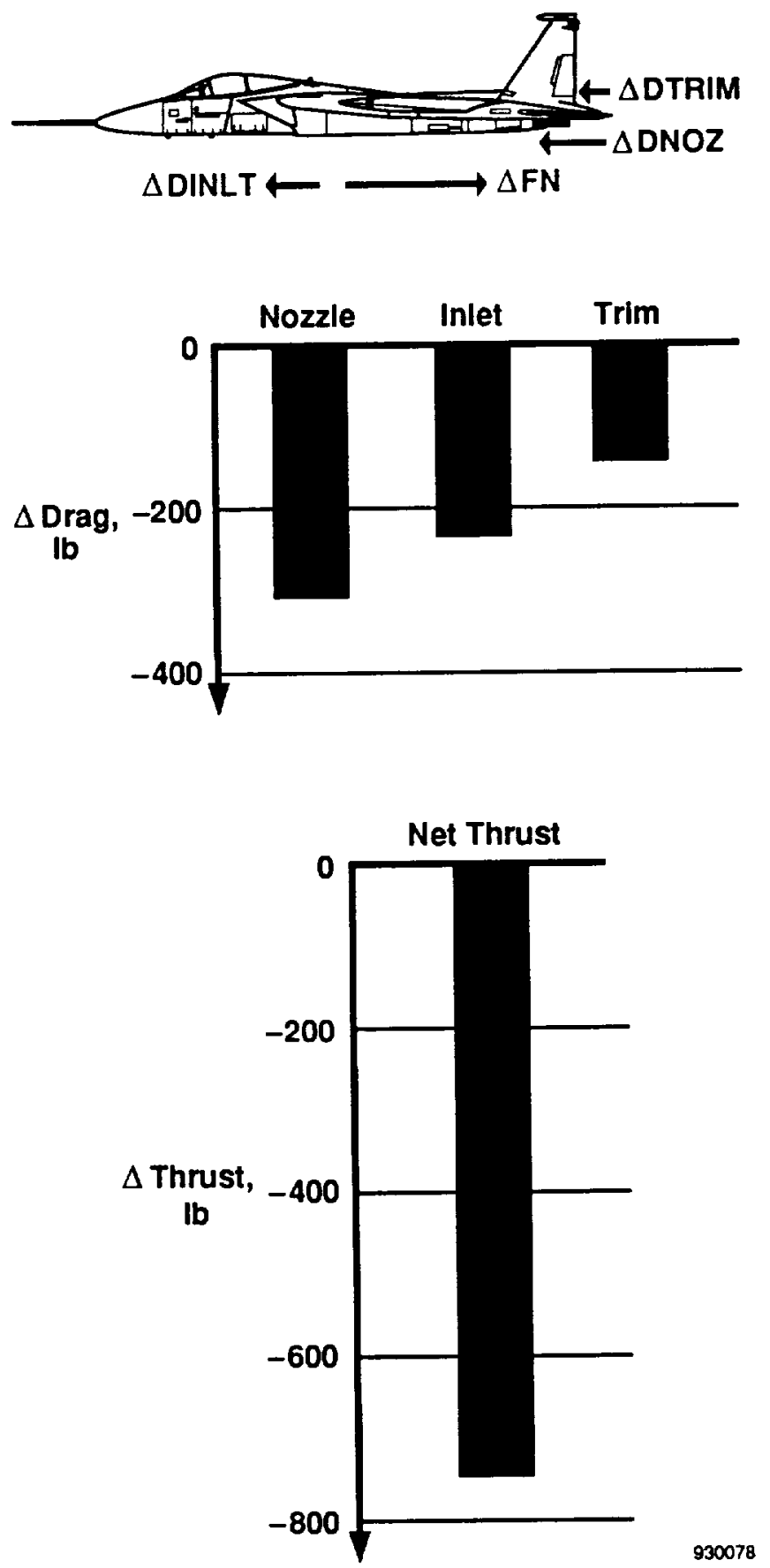

Fig. 12 Longitudinal aircraft forces for minimum fan turbine inlet temperature mode at Mach 1.80, at an altitude of $45,000 \mathrm{ft}$, and with $116^{\circ}$ power setting. 


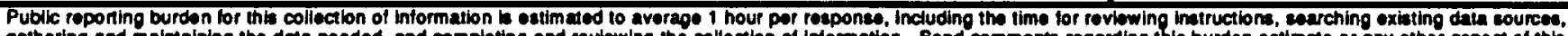
gathering and maintaining the deta noeded, and compioting and revlowing the collection of information. Send comments regarding this bunden estimate or any other aspect of thi Davis Hlghway. Suht 1204, Artington. YA 22202-4302, and to the Otfice of Management and Budget, Pepenwork Roduction Propet (0704-0188). Washington, DC 20503.

\begin{tabular}{l|l} 
1. AGENCY USE ONLY (Leave blank) & 2. REPORT DATE
\end{tabular} 3. AEPORT TYPE AND DATES COVERED June 1993 Technical Memorandum

4. TITLE AND SUBTITLE

Preliminary Supersonic Flight Test Evaluation of Performance Seeking Control

8. AUTHOR(S)

WU 533-02-34

John S. Orme and Glenn B. Gilyard

7. PERforming organization name(3) ANd address(ES)

8. PEAFORMING ORGANIZATION REPORT NUMBEA

NASA Dryden Flight Research Facility

P.O. Box 273

H-1909

Edwards, Califomia 93523-0273

5. FUNDING NUMBEAS

9. SPONSORING/MONITORING AGENCY NAME(S) AND ADDRESS(ES)

10. SPONSORING/MONITORING AGENCY REPORT NUMBER

National Aeronautics and Space Administration

Washington, DC 20546-0001

NASA TM-4494

11. SUPPLEMENTARY NOTES

Presented as AIAA-93-1821 at the 29th AIAASAE/ASME/ASEE Joint Propulsion Conference, June 28-30, 1993, Monterey, Califomia.

\begin{tabular}{l|l|l|}
\hline 12a. DISTRIBUTION/AVALABILITY STATEMENT & 12b. DISTRIBUTION CODE \\
Unclassified - Unlimited & \\
Subject Category 07 &
\end{tabular}

13. ABSTRACT (Maximum 200 words)

Digital flight and engine control, powerful onboard computers, and sophisticated controls techniques may improve aircraft performance by maximizing fuel efficiency, maximizing thrust, and extending engine life. An adaptive performance seeking control system for optimizing the quasi-steady state performance of an F-15 aircraft has been developed and flight tested. This system has three optimization modes: minimum fuel, maximum thrust, and minimum fan turbine inlet temperature. Tests of the minimum fuel and fan turbine inlet temperature modes were performed at a constant thrust. Supersonic single-engine flight tests of the three modes were conducted using varied afterburning power settings. At supersonic conditions, the performance seeking control law optimizes the integrated airframe, inlet, and engine. At subsonic conditions, only the engine is optimized. Supersonic flight tests showed improvements in thrust of 9 percent, increases in fuel savings of 8 percent, and reductions of up to $85^{\circ} \mathrm{R}$ in turbine temperatures for all three modes. This paper describes the supersonic performance seeking control structure and gives preliminary results of supersonic performance seeking control tests. These findings have implications for improving performance of civilian and military aircraft.

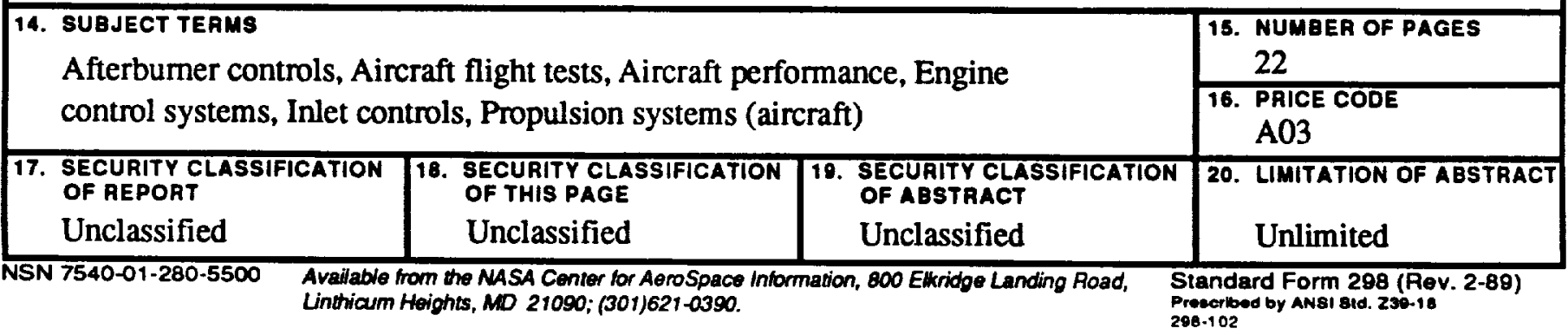

